\title{
Assessment of Healthcare Waste Generation Rate and Its Management System in Health Centers of Bench Maji Zone
}

\author{
Asrat Meleko ${ }^{1}$, Tarekegn Tesfaye ${ }^{2}$, Andualem Henok ${ }^{1 *}$
}

\author{
OPEN ACCESS \\ Citation: Asrat Meleko, Tarekegn Tesfaye \\ , Andualem Henok. Assessment of \\ Healthcare Waste Generation Rate and Its \\ Management System in Health Centers of \\ Bench Maji Zone. Ethiop J \\ Sci.2018;28(2):125. \\ doi:http://dx.doi.org/10.4314/ejhs.v28i2.4. \\ Received: June 10, 2017 \\ Accepted: July 25, 2017 \\ Published: March 1, 2018 \\ Copyright: (C) 2018 Asrat Meleko, et al . \\ This is an open access article distributed \\ under the terms of the Creative Commons \\ Attribution License, which permits \\ unrestricted use, distribution, and \\ reproduction in any medium, provided the \\ original author and source are credited. \\ Funding: Mizan-Tepi University \\ Competing Interests: The authors declare \\ that this manuscript was approved by all \\ authors in its form and that no competing \\ interest exists. \\ Affiliation and Correspondence: \\ ${ }^{1}$ Department of Public Health, Mizan- \\ Tepi University, Mizan, Ethiopia \\ ${ }^{2}$ Department of Pharmacy, Mizan-Tepi \\ University, Mizan, Ethiopia \\ *Email: andualemhenok@gmail.com
}

\begin{abstract}
BACKGROUND: It is known that the basic role of healthcare system is to preserve the health of patients and protect the public from diseases. However, in the process of performing these activities, health facilities generate hazardous waste that could be potentially harmful to healthcare workers, the public and the environment if there is insufficient handling, treatment and disposal of those wastes. Unfortunately, healthcare waste management is, in many regions, not yet carried out with a satisfactory degree of safety. Therefore, the aim of this study was to assess healthcare waste generation rate and its management system in health centers of Bench Maji Zone.

METHODS: A cross-sectional study was conducted from February to August, 2016. Observational checklist, key informant interview guide and weight scale were used to assess healthcare waste generation rate and its management system in selected health centers. Training, pre-test, instrument calibration and daily meeting were used to improve data quality. The Data was entered, compiled and analyzed using EpiData version 3.1 and SPSS version 21. The results on waste management system were reported using different descriptive statistics.

RESULTS: Out of the total HCW generated in health centers, more than half (57.9\%) was general or non-risk $\mathrm{HCW}$, and the remaining $42.1 \%$ was hazardous healthcare waste. The amount of $\mathrm{HCW}$ generated in the studied health centers was different from WHO's norm which may be attributed to different factors such as economy, patient flow, difference in services provided, poor waste segregation practice, available waste management system and seasonal factors.

CONCLUSION: HCW was not adequately managed which is characterized by lack of $\mathrm{HCW}$ segregation at source of generation and inadequate facilities to manage $\mathrm{HCW}$. Therefore, it is important to develop a HCW management plan for keeping human health as well environmental sustainability.

KEYWORDS: Healthcare waste, health center, healthcare waste generation rate, hazardous waste, general waste
\end{abstract}




\section{INTRODUCTION}

The growing concern on waste management increased the importance of proper health care management practices, especially in healthcare establishments due to its potential hazardous nature (1). It is known that the basic role of health care system is preventing and controlling of disease across the community (2). However, in the process of performing these activities, health facilities generate hazardous waste that could be potentially harmful to healthcare workers, the public and the environment (1).

According to the World Health Organization (WHO) related reports and studies, around 75$90 \%$ of health center wastes are general or nonhazardous, and the remaining $10-25 \%$ are infectious (3). The amount of healthcare waste produced and its characteristics depends on a number of factors such as type of Health Care Facilities (HCF) and the specific area within the HCF that generates the waste, established methods of waste management, degree of health facility specializations, proportion of reusable items employed in health care, and patient flow (4).

Healthcare waste management practice includes all activities involved in waste generation, segregation, transportation, storage, treatment and final disposal of the waste generated in the healthcare facilities. Although reliable records of the quantity and nature of healthcare wastes and the management techniques are lack, the problem related with healthcare waste management is more dominant in developing countries, including Ethiopia, which produce several hundreds of tons waste (5). In 2002 , the results of WHO assessment conducted in 22 developing countries showed that the proportion of healthcare facilities that did not use proper waste management was significant, ranging from $18 \%$ to $64 \%(6)$.

The healthcare waste management in Ethiopia is not much different from what is described above. One study done in Sidama Zone (Ethiopia) showed that $35 \%$ of the studied institutes collected and disposed syringes, needles or sharps in a manner that exposed workers and the general public to a risk (7). WHO confirms the risks among nurses associated to improper health care waste management such as transmission of $\mathrm{HBV}, \mathrm{HCV}$ and HIV/AIDS during health care delivery. The problem is observable across the globe even if the magnitude differs. According to WHO's (2007) report, it is estimated that around 23 million infections occurred due to improper management of healthcare waste globally (8).

The substantial human suffering and financial burden of these infections due to improper management of Health Care Waste (HCW) is staggering. Annually, in the United States, approximately 2 million patients develop Hospital Acquired Infections (HAI), and nearly 90,000 of these patients are estimated to die; this ranks HAI as the fifth leading cause of death in acute care health centers. It is also confirmed that at least 40 different pathogens were transmitted by sharp instruments and needle stick injuries (9).

The problem associated with healthcare waste management is extreme in developing countries. A study conducted in Northern Uganda revealed that $108(46 \%)$ of respondents assessed were found to have been exposed to potentially infectious body fluids due to improper HCW management (5). A cross-sectional survey conducted in Jimma Zone, Southwest Ethiopia shows that out of 174 health workers exposed to human immune deficiency virus risk, 105(60.3\%) sustained needle prick/cut by sharps, 77(44.3\%) were exposed to blood and 68(39.1\%) to patients' body fluid (18).

The dumping of medical waste in uncontrolled areas can have a direct environmental effect by contaminating soils and underground waters. Similarly, during incineration, if no proper filtering is done, it can be the primary source of some very toxic pollutants like Dioxin which is the main cause of cancer (10).

Risks associated with healthcare waste have gained attention across the world in various summits, locally and internationally. However, the impact of waste generated from healthcare facilities on human health and the environment

DOI: http://dx.doi.org/10.4314/ejhs.v28i2.4 
has often not been given significant attention from either the affected people or the concerned authorities including in Bench Maji Zone.

Thus, to minimize the risks associated with improper management of healthcare wastes, it is imperative to plan and develop evidence-based intervention strategy. However, data related with the magnitude of healthcare waste and existing management system does not exist in Bench Maji Zone.Therefore, the result from assessment of healthcare waste generation rate and its management system would provide data about waste generation rate by type and how healthcare wastes handled from the time of generation to ultimate disposal which could be important to develop systematic waste management practice in this zone.

\section{METHODS AND MATERIALS}

Study area and period: The data collection period was held from February to August 2016 in selected health centers of Bench Maji Zone. Bench Maji Zone is found in SNNPR (Southern Nations and Nationalities and Peoples' Region) which is located in Southwestern part of Ethiopia. The zone has 10 woredas (provinces) and 246 kebeles (smallest administrative unit). In this zone, there are 3 hospitals, 45 Health centers, both growing and functional. Of these, 39 are functional and the remaining 6 are on construction, and 224 health posts, totally 272 health facilities are available.

Study design: A cross-sectional study was conducted to assess health care waste generation rate and its management system of health centers in Bench Maji Zone.

Populations: The source population was all health centers in Bench Maji Zone. On the other hand, selected health centers from each woreda of Bench Maji Zone was the study population.

Sample size determination: A total of 10 health centers which were available in the zone were studied i.e. one health center from each woreda. It was assumed that health centers within one woreda may have nearly similar geographical conditions, life style and other variables. Initially, health centers within each woreda were listed. Then, from each woreda, one health center was selected using simple random sampling (lottery method) method to get the appropriate number of health centers to be investigated. Then, during data collection, all case teams or departments were included in the study.

Data collection tools and procedures: Observational checklist and weighting scale were used to assess the healthcare waste management system and its generation rate in each health center. First, a walk-through inspection of the health centers was done by the investigators in order to identify what type of waste generated in relation to the working section of the health center. Waste was collected and measured daily from Monday to Sunday consecutively, for seven days, to estimate the amount of the waste generated. Observational checklist and key informant interview were used to assess the management system.

To determine the magnitude of waste generated plastic buckets of different colors was used according to the type of waste generated based on WHO guideline. Thus, blue color for general waste, green color for pharmaceutical waste, red color for infectious waste and pathological waste and one safety box for sharp waste were distributed in different sections of the health center. The buckets, safety box and plastic bags were labeled to indicate the different categories of healthcare waste, date of collection and sample size. The actual data was collected for seven consecutive days with plastic bags which were kept inside in the buckets. Plastic bags were removed every morning and its weight was measured every day at 8:00 A.M using weighing scale. Information about waste management status was collected using observation check list.

Data analysis: The raw data collected from the field was entered and compiled using EPI INFO version 6.04 and SPSS - version 21. Significance testing was conducted using Spearman's rank correlation coefficient (rs) for testing the bivariate correlation between the total amount of waste and the number of patients. Patient flow and HCW generation rate were compared using KruskalWallis test. The results on assessment of healthcare waste management system were reported using different descriptive statistics. The 
average daily quantity of healthcare wastes in the health centers was computed. The annual waste generation rates were estimated based on the mean daily waste generation multiplying by the number of days in one year (365), assuming the activities related with waste generation are uniform, total $\mathrm{HCW}$ generation per year = Mean $\mathrm{HCW}$ generation in Kg per day * 365 .

Data quality management: Training was given to data collectors and supervisors before data collection. Weighing scales were calibrated every morning using a known weight before the actual measurements started. Daily on-site supervision was made by the supervisors during the actual measurements.

Ethical considerations: Ethical clearance was obtained from MTU Institute of Research and Community Support Development. Permission for data collection was obtained from Bench Maji zone Health department and respective Woreda Health offices. Verbal and written consent from the head of each health center was also taken prior to data collection.

\section{RESULTS}

Health care services: Out of the total health centers available in this zone, ten health centers were included in the study. The types of wards studied in those health centers were OPD (Outpatient Department), Pharmacy, Injection and dressing, $\mathrm{MCH}$ (Mother and Child Health), FP (Family Planning) and EPI (Expanded Program Immunization) room, TB room (tuberculosis follow-up unit), and delivery ward which are expected to be the source of various healthcare wastes.

Patient flow in the study health centers: A total of 8,476 patients visited in all 10 studied health centers within seven days of data collection time.
Of those total patients, 3,327(39.25\%) were found from OPDs. The mean $\pm \mathrm{SD}$ (standard deviation) of patient flow per day in all sections and at OPD in each health center was $121.1 \pm 31.37$ and $47.5 \pm 11.78$, respectively. More patients were visited Dizu HC, and on the other hand, less number of patients were found in Kibish Health Center.

Total healthcare waste generated in health centers: More than half (57.9\%) of the total HCW produced in all studied health centers was general or non-risk $\mathrm{HCW}$, and the remaining $42.1 \%$ was hazardous which requires special treatment and proper disposal measures to protect the health of the community and environmental.

Daily healthcare waste generation in Assessed Health Centers: The mean $( \pm$ SD) daily healthcare waste generation rate in all measured health centers was $2.716 \pm 0.736 \mathrm{~kg} /$ day, and of this $1.57 \pm 0.421 \mathrm{~kg} /$ day was general and $1.144 \pm 0.34 \mathrm{~kg} /$ day was hazardous. The quantity of healthcare waste generated within a day showed variation between studied health centers. It was identified that high amount of healthcare waste per day was generated at Yeteka Health Center $(3.79 \mathrm{~kg} /$ day $)$ while the least amount of healthcare waste was recorded at Maji Health Center (1.66 $\mathrm{kg}$ /day) (Table 1).

Healthcare waste generation rate by type in different health centers: The types of hazardous waste generated from studied health centers were sharps, infectious, pathological and pharmaceutical wastes. The mean $( \pm \mathrm{SD})$ generation rate of sharps, infectious, pathological and pharmaceutical waste in each health center was $0.267 \pm 0.107(23.3 \%), 0.2695 \pm 0.124$ (23.6), $0.441 \pm 0.157 \quad$ (38.6) and $0.166 \pm 0.058 \quad(14.5)$ $\mathrm{kg} /$ day, respectively (Table 2). 
Table 1: Quantity of HCW generated per day by type in studied health centers of Bench Maji Zone, SNNPR, 2016.

\begin{tabular}{lllll}
\hline \multicolumn{1}{c}{$\begin{array}{c}\text { Name of } \\
\text { Health Center }\end{array}$} & $\begin{array}{c}\text { Total HCW } \\
\text { in seven } \\
\text { days }\end{array}$ & $\begin{array}{c}\text { Average daily waste } \\
\text { generated in each HC }\end{array}$ & $\begin{array}{c}\text { Average daily } \\
\text { general waste } \\
\text { generated }\end{array}$ & $\begin{array}{c}\text { Average daily hazardous } \\
\text { waste generated in each } \\
\text { HC }\end{array}$ \\
\hline Yeteka HC & 26.56 & 3.79 & 2.06 & 1.73 \\
Bachuma HC & 16.08 & 2.30 & 1.52 & 0.78 \\
Tumi HC & 11.60 & 1.66 & 0.93 & 0.73 \\
Sheybench HC & 12.49 & 1.78 & 0.96 & 0.83 \\
Kibish HC & 20.58 & 2.94 & 1.75 & 1.19 \\
Jaba HC & 17.65 & 2.52 & 1.45 & 1.07 \\
Biftu HC & 22.70 & 3.24 & 1.96 & 1.28 \\
Genchi HC & 16.86 & 2.41 & 1.31 & 1.10 \\
Dizu HC & 26.28 & 3.75 & 2.11 & 1.65 \\
Jemo HC & 19.30 & 2.76 & 1.67 & 1.08 \\
Mean & 19.01 & 2.716 & 1.57 & 0.144 \\
Standard & 5.15 & 0.736 & 0.421 & \\
deviation & & & & \\
\hline
\end{tabular}

*HC - Health Center

Table 2: Distribution of types and amount of daily hazardous waste generation rate in health centers of Bench Maji Zone, SNNPR, 2016.

\begin{tabular}{lrrrrr}
\hline $\begin{array}{c}\text { Name of Health } \\
\text { Center }\end{array}$ & $\begin{array}{c}\text { Sharp waste } \\
\text { (kg/day) }\end{array}$ & $\begin{array}{c}\text { Infectious } \\
\text { waste } \\
\text { (kg/day) }\end{array}$ & $\begin{array}{c}\text { Pathological } \\
\text { waste (kg/day) }\end{array}$ & $\begin{array}{c}\text { Pharmaceutical } \\
\text { waste (kg/day) }\end{array}$ & $\begin{array}{c}\text { Total } \\
\text { hazardous } \\
\text { waste } \\
\text { (kg/day) }\end{array}$ \\
\hline Yeteka H C & 0.50 & 0.52 & 0.59 & 0.12 & 1.73 \\
Bachuma HC & 0.24 & 0.10 & 0.27 & 0.17 & 0.78 \\
Tumi HC & 0.17 & 0.09 & 0.36 & 0.10 & 0.73 \\
Sheybench HC & 0.29 & 0.23 & 0.15 & 0.16 & 0.83 \\
Kibish HC & 0.29 & 0.31 & 0.42 & 0.17 & 1.19 \\
Jaba HC & 0.17 & 0.29 & 0.43 & 0.18 & 1.07 \\
Biftu HC & 0.34 & 0.23 & 0.58 & 0.13 & 1.28 \\
Genchi HC & 0.14 & 0.28 & 0.53 & 0.15 & 1.10 \\
Dizu HC & 0.32 & 0.35 & 0.66 & 0.32 & 1.65 \\
Jemo HC & 0.21 & 0.30 & 0.41 & 0.16 & 1.08 \\
Mean & $\mathbf{0 . 2 6 7}$ & $\mathbf{0 . 2 6 9 5}$ & $\mathbf{0 . 4 4 1}$ & $\mathbf{0 . 1 6 6}$ & $\mathbf{1 . 1 4 4}$ \\
Std. deviation & $\mathbf{0 . 1 0 7}$ & $\mathbf{0 . 1 2 4}$ & $\mathbf{0 . 1 5 7}$ & $\mathbf{0 . 0 5 8}$ & $\mathbf{0 . 3 3 4}$ \\
\hline
\end{tabular}

*HC- Health centers

Healthcare waste generation rate depending on average patient flow in different health centers: Among the measured healthcare facilities Sheybench Heath Center generated the lowest ratio of healthcare waste per patient which was $0.0152 \mathrm{~kg} /$ patient/day while the largest proportion of healthcare waste per individual,

DOI: http://dx.doi.org/10.4314/ejhs.v28i2.4 
$0.016 \mathrm{~kg} / \mathrm{patient} /$ day, were contributed by Kibish Health Center.

Healthcare waste generation rate by wards: Large amounts of health care waste were generated from delivery ward, $6.74 \mathrm{~kg} /$ day with a mean $( \pm \mathrm{SD})$, of $0.674 \pm 0.23$ whereas TB followup room contributed the lowest portion of total healthcare waste generated, $2.622 \mathrm{~kg} /$ day with a mean $( \pm \mathrm{SD}), 0.262 \pm 0.071$.

Estimated amount of healthcare waste per year: The annual healthcare waste generation rate estimated per health center was found mean $( \pm \mathrm{SD}), 991.15 \pm 268.49 \mathrm{~kg} /$ year (Table 3).

Table 3: Estimated quantity of HCW generated per year among the study health centers, Bench Maji Zone, SNNPR, 2016

\begin{tabular}{lcccccc}
\hline Name of HC & $\begin{array}{c}\text { Estimated } \\
\text { patient } \\
\text { flow per } \\
\text { year }\end{array}$ & $\begin{array}{c}\text { Average } \\
\text { patient } \\
\text { flow per } \\
\text { day }\end{array}$ & $\begin{array}{c}\text { Daily HC } \\
\text { waste } \\
\text { generated in } \\
\text { each HC }\end{array}$ & $\begin{array}{c}\text { HCW } \\
\text { generated } \\
\text { per day } \\
\text { (g/pat/ day) }\end{array}$ & $\begin{array}{c}\text { Total } \\
\text { HCW } \\
\text { generation rate } \\
\text { per } \\
\text { year(kg/year) }\end{array}$ & $\begin{array}{c}\text { * Total } \\
\text { generation rate } \\
\text { per } \\
\text { year(kg/year) }\end{array}$ \\
\hline Yeteka HC & 46615.7 & 127.7 & 3.79 & 29.71 & 1384.91 & 1384.91 \\
Bachuma HC & 40097.9 & 109.9 & 2.30 & 20.91 & 838.41 & 838.41 \\
Tumi HC & 34779.3 & 95.3 & 1.66 & 17.39 & 604.70 & 604.70 \\
Sheybench HC & 42757.1 & 117.1 & 1.78 & 15.23 & 651.00 & 651.00 \\
Kibish HC & 32537.1 & 89.1 & 2.94 & 32.98 & 1072.94 & 1072.94 \\
Jaba HC & 35092.1 & 96.1 & 2.52 & 26.22 & 920.06 & 920.06 \\
Biftu HC & 60955 & 167 & 3.24 & 19.42 & 1183.64 & 1183.64 \\
Genchi HC & 47658.6 & 130.6 & 2.41 & 18.45 & 879.13 & 879.13 \\
Dizu HC & 66012.9 & 180.9 & 3.75 & 20.76 & 1370.31 & 1370.31 \\
Jemo HC & 35457.1 & 97.1 & 2.76 & 28.38 & 1006.36 & 1006.36 \\
Mean & 44196.3 & $\mathbf{1 2 1 . 1}$ & 2.72 & 22.94 & 991.15 & 991.15 \\
Std. Deviation & 11437.8 & $\mathbf{3 1 . 3 7}$ & 0.74 & 5.95 & 268.49 & 268.49 \\
\hline
\end{tabular}

$* *$ Total HCW generation rate in $\mathrm{kg}$ per year $=\mathrm{HCW}$ generation rate in $\mathrm{kg}$ per day $* 365$

$*$ Total $\mathrm{HCW}$ generation rate in $\mathrm{kg}$ per year $=(\mathrm{HCW}$ generation rate in $\mathrm{g}$ per patient per day $*$ No of annual patient flow) $/ 1000$

Comparison between patient flow and healthcare waste generation rate: To check the presence of significant difference among health centers with regard to average patient flow, total healthcare waste, general waste and hazardous waste Kruskal-Wallis test was used. According to the result, there was a statistically a significant difference between means of healthcare waste generated $(\chi 2=20.068, \mathrm{p}$ value $=0.017)$ and general waste generated $(\chi 2=25.822, \quad p$ value $=0.002$ ) among study health centers. However, statistically significant difference was not observed for patient flow $(\chi 2=4.586$, pvalue $=0.869)$, and mean of hazardous waste $(\chi 2=6.821, p$-value $=0.656)$ among studied health centers in Bench Maji zone (Table 4).

Spearman's rank correlation coefficient $\left(r_{s}\right)$ was used for testing the existence of any bivariate correlation between the total number of patients and the total amount of healthcare waste generated. Accordingly, in most health centers, there was a positive linear relationship between amount of healthcare waste generated and total patient flow. Strong relations were observed in Semen Bench Health Center while weak bivariate relation between patient flow and total healthcare waste generated were observed in Maji Health Center (Table 5).

DOI: http://dx.doi.org/10.4314/ejhs.v28i2.4 
Table 4: Comparison between patient flow and health care waste generation rate among the study health centers, Bench Maji Zone, SNNPR, 2016.

\begin{tabular}{lcccc}
\hline Name of HC & \multicolumn{3}{c}{ Mean rank } \\
\cline { 2 - 5 } & Patient flow & Total HCW & General waste & Hazardous waste \\
\hline Yeteka HC & 38.50 & 46.07 & 48.57 & 40.71 \\
Bachuma HC & 35.07 & 33.50 & 33.50 & 26.50 \\
Tumi HC & 30.21 & 15.57 & 14.71 & 25.93 \\
Sheybench HC & 35.21 & 21.71 & 16.43 & 34.36 \\
Kibish HC & 28.07 & 44.57 & 43.29 & 37.79 \\
Jaba HC & 32.50 & 31.86 & 36.00 & 33.50 \\
Biftu HC & 43.29 & 42.64 & 47.00 & 38.07 \\
Genchi HC & 36.71 & 29.57 & 24.79 & 33.43 \\
Dizu HC & 44.71 & 52.86 & 50.57 & 49.00 \\
Jemo HC & 30.71 & 36.64 & 40.14 & 35.71 \\
Chi-square & 4.586 & 20.068 & 25.822 & 6.821 \\
Asymp. Sig. & 0.869 & 0.017 & 0.002 & 0.656 \\
\hline
\end{tabular}

Degree of freedom $=9$

Table 5: Relation of visitors and amount of healthcare waste in study health centers, Bench Maji Zone, SNNPR, 2016.

\begin{tabular}{ll}
\hline $\begin{array}{l}\text { Name of Health } \\
\text { Center }\end{array}$ & $\begin{array}{l}\text { Spearman's } \\
\text { correlation coefficient }\end{array}$ \\
\hline Yeteka HC & 0.576 \\
Bachuma HC & 0.571 \\
Tumi HC & 0.071 \\
Sheybench HC & 0.572 \\
Kibish HC & 0.393 \\
Jaba HC & 0.179 \\
Biftu HC & 0.143 \\
Genchi HC & 0.786 \\
Dizu HC & 0.929 \\
Jemo HC & 0.679 \\
\hline
\end{tabular}

Healthcare waste management practice: Only, two (2), of the assessed health centers were practicing healthcare waste segregation at source of generation during data collection time. All health centers had no healthcare waste recycling or reusing mechanism. In all studied health centers, there was no separate place for storing wastes temporarily and any clearly stated program to collect wastes from different departments. During data collection, only waste handlers in 4 health centers used gloves during collection and transportation of healthcare wastes. The waste disposal methods in use by studied health centers were incinerator, open pit burning, small burial and placenta pit. Of the total health centers, 5 had functional incinerators during data collection time. However, all of the 5 health centers who had incinerator were using it as disposal method for different unidentified wastes including non-combustible waste. It was noted that all of the health centers observed did not have a well-organized structure or system for dealing with HCW (Table 6). 
Table 6: Health care waste management practice among the study health centers, Bench Maji Zone, SNNPR, 2016.

\begin{tabular}{lll}
\hline Variable & Yes , N=10 & No, N=10 \\
\hline Onsite segregation of waste in to hazardous and general & 2 & 8 \\
Separate waste collection container & 4 & 6 \\
Containers are clearly marked and coded & 1 & 5 \\
Containers are available everywhere they needed & 0 & 4 \\
Temporary HC waste storage container & 4 & 6 \\
HCW transportation container are with lid & 0 & 10 \\
Temporary waste storage site & 0 & 10 \\
Have functional incinerator & 5 & 5 \\
Have placenta pit & 6 & 4 \\
Have waste management committee, adequate fund and standard & 0 & 10 \\
procedures to manage health care waste & & \\
\hline
\end{tabular}

\section{DISCUSSION}

Estimation of annual healthcare waste generation rate was done using two important methods. Accordingly, estimated annual mean $( \pm \mathrm{SD})$ of healthcare waste generation rate per health center was $991.15 \pm 268.49 \mathrm{~kg} /$ year. The estimation of annual mean healthcare waste generation rate was done with a preferred assumption. This result was higher than a result obtained in Gojjam (11) which may be associated with variation of annual patient flow and seasonal variation.

The result from this study revealed that $57.9 \%$ of the total $\mathrm{HCW}$ produced in measured health centers of this zone was general and the remaining $42.1 \%$ was hazardous health care waste. Of the total hazardous waste stream sharps, infectious and pathological wastes constitutes with mean $( \pm$ SD) $0.267 \pm 0.107$ $(23.3 \%), 0.2695 \pm 0.124$ (23.6\%), $0.441 \pm 0.157$ $(38.6 \%)$ respectively in all health centers. While the rest were pharmaceutical, $0.166 \pm 0.058$ $(14.5 \%) \mathrm{kg} /$ day, which was not coherent with WHO guideline. The norm, according to the WHO guidelines, is that health centers produce $75 \%$ to $85 \%$ general healthcare waste, and $10 \%$ to $25 \%$ hazardous healthcare waste (12). Also, it was much higher than a result obtained in a study done in Ilembe Woreda (13) but was much closer to a result obtained in a study done in Gojjam Zone by Muluken A and Abera K (11). This difference may be attributed to large numbers of attendants in healthcare facilities during data collection, lack of appropriate HCW segregation practice according to WHO guideline and absence of any reusing or recycling activities (4).

The average daily, with mean $( \pm \mathrm{SD})$, healthcare waste generation rate in all measured health centers was $2.716 \pm 0.736 \mathrm{~kg} /$ day or $0.023 \mathrm{~kg} /$ patient $/$ day. This result was a bit higher than a result obtained in Tanzania with a value of $0.02 \mathrm{~kg} /$ patient/day (5). However, it was much lower than a result found in a study done in Addis Ababa $(8.66 \pm 10.95 \mathrm{~kg} /$ day (17) and Gojjam $\quad(1.79 \pm 0.57 \quad \mathrm{~kg} / \mathrm{day}$ or 0.035 $\mathrm{kg} /$ patient/day) (11).

There was a significant difference in the total healthcare waste generation rate between studied healt centers with $\left(\chi^{2}=20.068, \mathrm{p}\right.$ value $=0.017$ ). This may be attributed to the status of patient flow and resource allocation to the health centers. However, there was no significance difference $(\chi 2=4.586, p$-value $=0.869)$ for patient flow between studied health centers. This result was similar with a result obtained in studied health centers of Addis Ababa (14).

According to this study, out of 10 health centers assessed only 2 of them segregate healthcare waste at source of generation with buckets properly labeled and identified. This result was comparably similar with a result obtained in Gojjam Zone where waste minimization and segregation of wastes were not employed by any of the health institution investigated (11). Also, it was similar with 
another study done in Addis Ababa which revealed that almost all of the studied healthcare facilities reported as there was no segregation of waste into infectious, pathological and pharmaceutical, and had no separate bins for the collection of infectious waste (14). However it was much lower from a result found in Ilembe District where all the healthcare facilities assessed indicated that they are separating waste into five categories appropriately (13). This may be attributed to absence of training programs for health professionals and ancillary staff about segregation, absence of clear standards with regard to the principle of $\mathrm{HCW}$ segregation and may be low enforcement by the top management (2).

Waste has to be stored before collection and final disposal, and should not accumulate in corridors, wards or places that are accessible to the general public (3). However, in all studied health centers, there were no separate places for storing $\mathrm{HCW}$ temporarily before it is taken to final disposal or treatment site.

Safe transportation of high-risk HCW items such as sharps and infectious wastes is needed to prevent accidental injuries and infection to anyone who comes into contact with it during transit. Collection and transportation of medical waste must be carried out by trained personnel from authorized waste collection companies. Also, all containers should be covered and labeled as being bio-hazard according to WHO specifications. HCW should be collected daily and transported to temporary storage site or to final disposal site (15). In the studied health centers, different types of healthcare wastes such as infectious and general wastes were not transported separately with separate transporting device. More than half of the studied health centers had transporting containers which were not appropriately sealed and treated with disinfectants. All of the findings in relation with storage, collection and transportation of $\mathrm{HCW}$ did not correspond with the requirement by the WHO and national guidelines for daily and frequent collection and transportation of clinical waste (16).

A result from this study revealed that out of the total health centers assessed, 5 of them had functional incinerator during data collection time with a number of limitations. However all the 5 health centers used incinerator as disposal method of different unidentified wastes including non-combustible waste. The remaining 5 health centers use open burning for removing wastes from the environment. This result was similar with the results of other studies done in Ethiopia by the $\mathrm{MoH}$ in 16 health centers and 48 clinics where most of them had no proper liquid waste and solid waste disposal facilities (17) and Gojjam Zone (11). Thus, it was not coherent with the national rule and regulations of HCWM system. This may be associated with lack of well-organized working committee, low budget for HCWM, and absence of healthcare waste management rules and regulations in all health centers (10).

The mean healthcare waste generation in this study was not in line with the estimated norms of WHO. This is associated with poor practice of waste segregation at source of generation as well as non-integrated waste management system. Healthcare waste management practice includes all activities starting from on-site waste minimization. According to our results, the commonest observed problems were poor or inadequate onsite segregation, collection and transportation practice. Local and federal government shall work to halt the problem.

\section{REFERENCES}

1. Dasimah O, Siti N, and Subramaniam A. Clinical Waste Management in District Hospitals of Tumpat,Batu Pahat and Taiping. Procedia - Social and Behavioral Sciences. 2012; 68: 134-145.

2. Mumtaz H. Awareness About hospital Wastes And Its Effects On The Health Of Patients In District of Dera Ghazi Khan. Asian Journal Of Applied Science And Engineering. 2014; 3: 41-48.

3. Pruss W, Townend K. Management of wastes from health-care activities Geneva: World Health Organization (WHO); 1999.

4. Tabasi R and Marthandan G. Clinical Waste Management: A Review On Important Factors In Clinical Waste Generation Rate. 
International Journal of Science And Technology. 2013; 3:194-200.

5. Mwesigye P. Integrated Assessment Of Present Status Of Environmentally -Sound Management Of Wastes In Africa. Africa Review Report On Waste Management. Addis Ababa, Ethiopia: Economic Commsion For Africa; 2009.

6. Mesfin K, Kassahun A, Andamlak G. et al. Assessment of the health care waste generation rates and its management system in hospitals of Addis Ababa, Ethiopia, 2011. BMC Public Health. 2013; 13(28).

7. Yosef W. Assessment of the Safety of Injections and Related Medical Practices in Health Institutions at Sidama Zone, SNNPR, Ethiopia. Addis Ababa University: MPH Thesis. 2004.

8. World Health Organization (WHO). WHO core principles for achieving safe and sustainable management of health-care waste. 2007.

9. Nelson's P. Patient safety climate :variation in perceptions by infection preventionist and quality directors. 2011

10. Hossain, M. Clinical Solid Waste Management Practices And Its Impact On Human Health And Environment -A Review. Waste Management. 2010.doi:10.1016/j.wasman.2010.11.008

11. Muluken A and Abera K. Healthcare waste generation and its management system: the case of health centers in West Gojjam Zone, Amhara Region, Ethiopia. Ethiop. J. Health Dev. 2010; 24(2): 119-126.
12. World health organization (WHO). Starting Health Care Waste Management In Medical Institutions. Healthcare Waste Information Series. 2000.

13. Gabela S. Health Care Waste Management In Public Clinics in the Ilembe District: A Situational Analysis. Durban. Health Systems Trust. 2007.

14. Department HaEH: Health Care Waste Management National Guidelines. Edited by Federal Ministry of Health HaEHD. Addis Ababa, Ethiopia; 2007.

15. The Federal Environmental Protection Authority. Technical Guidelines on the Environmentally Sound Management of Biomedical and Healthcare Wastes Addis Ababa, Ethiopia: The Federal Environmental Protection Authority; 2004.

16. Environmental Health Department. Healthcare waste handling and disposal guidance. Edited by Ministry of Health HaEHD. 1990.

17. Legesse $M$ and Kumie A. Healthcare waste generation and management practice in government health centers of Addis Ababa, Ethiopia. BMC Public Health 2014; 14:1221.

18. Hailu C and Tebeje B. Assessment Of HIV Post-Exposure Prophylaxis Use Among Health Workers Of Governmental Health Institutions In Jimma Zone, Oromiya Region Southwest Ethiopia. Ethiopian journal of health sciences. 2010; 20(1):55-64. 